Syntactic representations contain semantic information: Evidence from forced-choice comprehension and syntactic-priming studies of the passive with adults and children

\author{
Amy Bidgood* ab \\ Caroline F. Rowland ${ }^{\text {bc }}$ \\ Julian M. Pine ${ }^{a b}$ \\ Ben Ambridge ${ }^{a b}$
}

* Corresponding Author

${ }^{a}$ Department of Psychological Sciences, Eleanor Rathbone Building, University of Liverpool, Liverpool, L69 7ZA, UK.

${ }^{\mathrm{b}}$ ESRC International Centre for Language and Communicative Development (LuCiD),

Department of Psychological Sciences, Eleanor Rathbone Building, University of Liverpool, Liverpool, L69 7ZA, UK.

${ }^{c}$ Max Planck Institute for Psycholinguistics, Wundtlaan 1, 6525 XD Nijmegen, The Netherlands.

Email addresses: amy.bidgood@livêrpool.ac.uk; caroline.rowland@mpi.nl; ipine@liverpool.ac.uk; ambridge@liverpool.ac.uk 


\title{
Syntactic representations contain semantic information: Evidence from forced-choice comprehension and syntactic-priming studies of the passive with adults and children
}

\begin{abstract}
A key question in language research is whether linguistic representations contain semantic information. A number of studies of the English passive have found that, for both children and adults, performance varies as a function of the semantic type of the verb. Other studies of this construction have found equal performance across verbs, supporting a semantics-free view of syntax and its acquisition. Here we use new comprehension and priming studies to test if children's and adults' comprehension and production of passives varies according to semantic verb type. The comprehension study showed verb-type differences for both children (aged 4-6 years) and adults, suggesting that semantic restrictions on the passive construction exist, and continue into adulthood. In the priming study, both children (aged 4-6 years) and adults produced more passives following passive than active primes, demonstrating that their knowledge of the passive is "abstract" in the sense that it is not tied to particular lexical items. At the same time, we also found evidence for a semantic constraint on the passive in that - across children and adults, and across comprehension and production - themeexperiencer verbs (e.g. annoy) showed the highest degree of passivisability and experiencertheme verbs (e.g. see) the least, with agent-patient verbs (e.g. hit) intermediate. We end by considering three classes of accounts that could potentially explain these findings; those based on (a) autonomy of syntax, (b) a semantic construction prototype and (c) pure exemplar storage and analogy.
\end{abstract}

Keywords: passive construction; comprehension; syntactic priming; autonomy of syntax; semantic prototype construction; exemplar model.

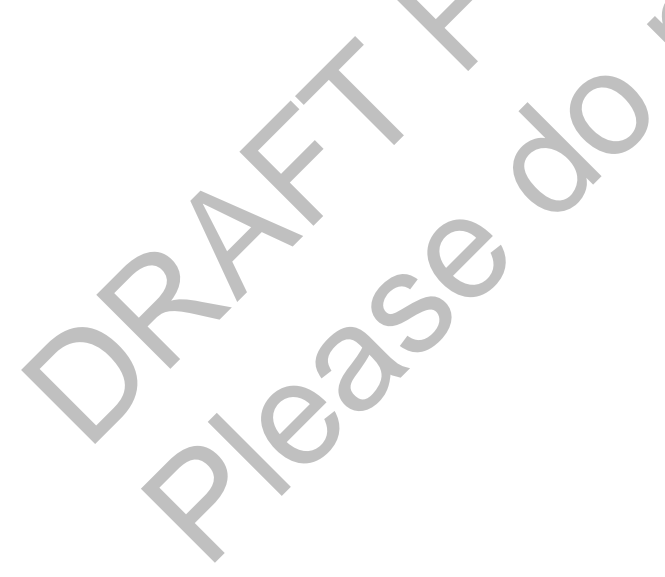




\section{Syntactic representations contain semantic information: Evidence from forced-choice comprehension and syntactic-priming studies of the passive with adults and children}

A debate that lies at the heart of language acquisition research is whether speakers' syntactic representations are fully abstract or semantically constrained, and whether this changes across development. Full-abstraction accounts assume that linguistic rules and generalisations apply to categories (e.g. VERB), rather than to individual items (e.g. hit, annoy, see), and hence hold across all members of the category, regardless of their semantics. In the adult psycholinguistic literature, this claim is often referred to as autonomy of syntax; the assumption that "grammar is autonomous and independent of meaning" (Chomsky, $1957^{1}$ ); or that "syntactic representations do not contain semantic information" (Branigan \& Pickering, 2017: 8). In the language acquisition literature, early-abstraction accounts (e.g. Gertner, Fisher \& Eisengart, 2006; Valian, Solt \& Stewart, 2009; Yang, 2013) argue that children represent language on this abstract structural level from the beginning of development.

Semantic-constraint accounts assume that speakers' representations are not fully abstract - in the sense of applying to all members of a particular category, regardless of their semantics - but contain, and are sensitive to, semantic information. For example, Schlesinger (1981) argues that the syntactic category of SUBJECT has its origins in the semantic category of AGENT and, as such, retains the "semantic flavour of agency" (1981: 241), even in the adult grammar. On this view, a sentence such as ?The wind closed the door is somewhat less acceptable than The man closed the door, because - although both the wind and the man are syntactic subjects - the latter exhibits a greater degree of agency. In the language acquisition literature, proposals under which syntactic categories such as SUBJECT and OBJECT develop from semantic categories such as AGENT and PATIENT have been developed by researchers with otherwise-very-different theoretical perspectives, including Pinker (1989) and Tomasello (2003).

The debate between full-abstraction and semantic-constraint accounts is played out particularly clearly in research on acquisition of the English passive (e.g. Messenger, Branigan, McLean \& Sorace, 2012, vs. Maratsos, Fox, Becker \& Chalkey, 1985). The reason that this construction constitutes a particularly useful test case is that it is one of the few for

\footnotetext{
${ }^{1}$ With regard to the passive, Chomsky (1993: 4) goes further, specifically denying the existence of the passive as an independent grammatical construction: "Constructions such as. . . [the] passive remain only as taxonomic artifacts, collections of phenomena explained through the interaction of the principles of UG, with the values of the parameters fixed.
} 
which children (and even some adults; e.g. Dabrowska \& Street, 2006) make errors, particularly in comprehension (e.g. Maratsos et al., 1985; Sudhalter \& Braine, 1985; Gordon \& Chafetz, 1990; Fox \& Grodzinksky, 1998; Meints, 1999; Hirsch \& Wexler, 2006).

A number of early studies of the passive, mostly using forced-choice comprehension, provided support for semantic-constraint accounts. These studies suggest that children experience greater difficulty with passive sentences that contain mental-state (or "psychological") verbs (e.g. Bob was seen by Wendy) than actional verbs (e.g. Bob was hit by Wendy). For example, Maratsos et al. (1985) used a sentence comprehension task to compare young children's (aged from 4 to 11 years) understanding of active and passive sentences using (a) prototypical actional verbs (agent-patient verbs, e.g. hold) and (b) mental verbs (experiencer-theme verbs, e.g. like). All children performed above chance with both verb types in active sentences (e.g. Batman holds Donald [Duck], Batman sees Donald) and with agent-patient verbs in passive sentences (e.g. Donald is held by Batman). In contrast, children as old as 7 years struggled with experiencer-theme verbs in passive sentences (e.g. Donald is seen by Batman). Similar findings have been observed in other comprehension and production studies (e.g. Sudhalter \& Braine, 1985; Pinker, Lebeaux and Frost, 1987; Gordon \& Chaftez, 1990, Meints, 1999), and in naturalistic data (e.g. Israel, Johnson \& Brooks, 2000). These findings are taken (e.g. in Maratsos et al., 1985) as evidence for the claim that children begin with a prototypical passive construction, which involves verbs with a high degree of actionality or passive-subject-affectedness; i.e. agent-patient verbs (e.g. hit). With development, this representation is gradually broadened to include theme-experiencer (e.g. annoy) and, finally, experiencer-theme verbs (e.g. see); although even in adults, the "semantic flavour" (Schlesinger, 1981) of the construction persists. For example, verbs that exhibit extremely low actionality/affectingness cannot appear in the passive construction at all (e.g. * 1 lb was weighed by the package; Five people are slept by this tent).

A number of more recent studies, mostly using syntactic priming (see Branigan, 2007; Pickering \& Ferreira, 2008; Branigan \& Pickering, 2017, for reviews), have provided support for full-abstraction accounts. These studies found that, even for children as young as $3 ; 0$, hearing a passive sentence increases the likelihood of subsequently producing a passive sentence with a different verb (e.g. Savage, Lieven, Theakston \& Tomasello, 2003; 2006; Huttenlocher, Vasilyeva \& Shimpi, 2004; Bencini \& Valian, 2008; Messenger, Branigan \& McLean, 2011a; 2011b). The assumption is that syntactic priming effects reflect the activation of a stored abstract construction (e.g. Branigan, Pickering, Liversedge, Stewart \& Urbach, 1995), and thus that the existence of such an effect for passives demonstrates abstract 
knowledge of this construction amongst young children. Similar findings have also been observed for adults (Bock, 1986; Bock \& Loebell, 1990; Bock, Loebell \& Morey, 1992). Further evidence for early abstract knowledge of the passive comes from a recent preferential looking study (Messenger \& Fisher, 2018), in which 3-year-olds interpreted passives with novel verbs (e.g. She's getting snedded by the boy) as referring to the correct target event (e.g. a boy performing a novel action on a girl, rather than vice versa). Nevertheless, while these studies certainly provide evidence for impressively early knowledge of the passive, they do not directly address the question of a possible semantic constraint on this construction, since none systematically manipulated verb semantics.

Messenger et al. (2012) conducted production-priming and forced-choice comprehension tasks designed to investigate this question; and, specifically, the possibility that children's early knowledge of the passive is indeed abstract (in the sense of applying equally to all verbs), and that the by-verb differences observed in previous studies (e.g. Maratsos et al., 1985) could be explained by task effects. They argue that, because depicting non-actional events in experimental materials is more difficult than depicting events involving agent-patient verbs, poor picture recognition may account for these results. Messenger et al.'s comprehension task replicated the findings of previous studies (e.g. Maratsos et al., 1985), with young children showing less accurate comprehension of passives with psychological experiencer-theme verbs (e.g. see) than agent-patient (e.g. hug), and psychological theme-experiencer (e.g. annoy) verbs. Taken in isolation, this finding is consistent with semantic-constraint accounts. However, in contrast to Maratsos et al.'s (1985) findings (see also Hirsch \& Wexler, 2006), Messenger et al. (2012) also found this pattern with active sentences, supporting their claim that it is experiencer-theme verbs (or depictions of such verbs) that are problematic for children, rather than experiencer-theme passives.

Another notable aspect of Messenger et al.'s (2012) comprehension study - and one that has particular relevance for the present study - is the three-way distinction drawn between agent-patient (e.g. hug), experiencer-theme (e.g. see) and theme-experiencer (e.g. annoy) verbs. Maratsos et al. (1985) did not include theme-experiencer verbs in their stimuli, and instead drew a distinction between "physical action" (all agent-patient) and "mental" verbs (all experiencer-theme). In fact, the findings of Messenger et al. (2012) suggest that semantically (or at least in terms of how easily they can be depicted), theme-experiencer verbs (e.g. annoy), although, in some sense, "psychological” verbs, are more akin to actional agent-patient verbs (e.g. hug) than to psychological experiencer-theme verbs (e.g. see) 
Messenger et al.'s (2012) conclusion of no passive disadvantage for experiencertheme verbs was supported by two production-priming studies reported in the same paper. Participants - both children and adults - took turns with an experimenter to describe pictures in which an animal was performing an action on a human (e.g. a sheep hitting/shocking a girl). The experimenter produced an active or passive sentence containing either an agentpatient or a theme-experiencer verb (Experiment 1) or a theme-experiencer or an experiencer-theme verb (Experiment 2). Participants' pictures always depicted an actional event, designed to be described using an agent-patient verb (e.g. scratch, wash, hug). Messenger et al. found no difference in the rate of passives produced following different prime constructions (agent-patient/theme-experiencer/experiencer-theme), and this finding was the same for both adults and children. They therefore concluded that children have fully abstract knowledge of passive syntax by 3-4 years of age, with no evidence for a semantic constraint on the passive for either children or adults.

A subsequent study of adults, however, provided some support for semanticconstraint accounts. Ambridge, Bidgood, Pine, Rowland and Freudenthal (2016) conducted graded grammaticality judgment and timed forced-choice comprehension studies (both of which have the advantage of yielding a continuous, rather than binary, dependent measure). After controlling for both overall verb frequency and verb frequency in the passive construction, Ambridge et al. (2016) found that both adults' judgments of grammatical acceptability and their reaction times for choosing the correct animation in the forced-choice comprehension task were predicted by affectedness ratings (provided by a separate group of participants). These ratings were designed to capture the extent to which each verb exhibits semantics consistent with those of the passive construction itself, as defined by Pinker et al. (1987: 249) as follows:

[B] (mapped onto the surface subject [of a passive]) is in a state or circumstance characterised by [A] (mapped onto the by-object or an understood argument) having acted upon it.

Arguing for the latter possibility, Pinker et al. (1987: 249; see also Pinker, 1989) propose that passivisation is restricted to verbs that denote actions or events such that [B] (mapped onto the surface subject [of a passive]) is in a state or circumstance characterised by [A] (mapped onto the by-object or an understood argument) having acted upon it. 
Importantly, semantic effects for both grammaticality judgments and reaction times were significantly larger for the passive than the active construction. That is, the observed disadvantage for low-affectedness verbs (e.g. see) was greater for the passives than actives, and so cannot be explained simply as a general difficulty with processing or depicting lowaffectedness verbs.

This raises the question of why no semantic effects on the passive were observed by Messenger et al. (2012), for either children or adults, in either comprehension or production priming. The aim of the present study is to investigate this question, and, in so doing, mediate more definitively between full-abstraction and semantic-constraint accounts.

With regard to comprehension (the present Study 1), one possibility is that the difficulty of illustrating non-actional verbs in general, and experiencer-theme verbs in particular, was exacerbated by Messenger et al.'s (2012) use of still pictures. In the present comprehension study (Study 1), we aim to reduce this difficulty via the use of animations and - for adults - a more sensitive dependent measure: reaction time to select the matching picture, rather than simply correct/incorrect (which is crucial since, in the present study, adults show 96\% correct performance). Full-abstraction accounts predict that, for both children and adults, any impairment for passive sentences (relative to active control sentences) will not differ according to the semantic type of the verb (agent-patient / themeexperiencer / experiencer-theme), as any such impairment is due solely to the difficulty of illustrating particular actions, and so will hold for both passives and actives equally. That is, full-abstraction accounts predict that we will essentially replicate the findings of Messenger et al. (2012). In contrast, semantic-constraint accounts predict an interaction such that, for both adults and children, the extent of participants' impaired performance with passive sentences (relative to active control sentences) will be greater for experiencer-theme verbs (e.g. see) than for agent-patient verbs (e.g. hit), since children start out with a prototypical passive construction built around agent-patient verbs (Maratsos et al., 1985), whose "semantic flavour" (Schlesinger, 1981) persists into the adult passive construction (Ambridge et al., 2015).

The prediction of semantic-constraint accounts with regard to theme-experiencer verbs is less clear, as it depends on the exact nature of the semantic constraint assumed. On the basis of the traditional distinction between actional and psychological/mental-state verbs (e.g. Maratsos et al., 1985), we might expect psychological theme-experiencer verbs (e.g. annoy) to pattern more like psychological experiencer-theme verbs (e.g. see) than actional agent-patient verbs (e.g. hit), or to be intermediate between the two. However, on the basis of 
the "affectedness" constraint outlined by Pinker et al. (1987), we might expect themeexperiencer verbs (e.g. annoy) to pattern more like actional-agent patient verbs (e.g. hit), or even to make better passives. After all, theme-experiencer verbs - almost by definition entail that the passive subject is affected (e.g. Bob was annoyed/scared by Wendy, ?but, actually, he didn't notice). Agent-patient verbs imply that the passive subject is affected, often considerably so (e.g. Bob was hit/kicked by Wendy...), but do not actually entail it (...but, actually, he didn't notice). Indeed, an adult production study (Ferreira, 1994) found that adults produced passives at higher rates (31\%) with theme-experiencer verbs (e.g. annoy) than agent-patient (e.g. hit) and experiencer-theme verbs (e.g. see), which were collapsed into a single category. A secondary aim of the present study is to therefore clarify the status of theme-experiencer verbs with regard to the passive.

With regard to production priming (the present Study 2) one possible explanation for Messenger et al.'s (2012) null finding for semantic verb type is that Messenger et al. varied the semantic type of the prime verb (agent-patient/theme-experiencer/experiencer-theme) while holding constant the semantic type of the target verb (agent-patient). A number of previous studies have shown that the identity of the target verb can affect the size of the priming effect (e.g. Coyle \& Kaschak, 2008; Peter, Chang, Pine, Blything \& Rowland, 2015). Thus, if semantic-constraint accounts are correct in their assumption that agent-patient verbs are the prototypical type for passive sentences, using only agent-patient verbs as targets may reduce the likelihood of observing by-verb differences. That is, even a prime verb whose semantics are less than fully compatible with the semantics of the passive construction (e.g. an experiencer-theme verb) may still yield a "good enough" passive to prime production of an "easy" agent-patient passive. In the present production priming study (Study 2), we therefore reverse the design of Messenger et al. (2012) by varying the semantic type of the target verb (agent-patient/theme-experiencer/experiencer-theme), while holding constant the semantic type of the prime verb (agent-patient). We suggest that this small manipulation is likely to result in a more sensitive test of possible by-verb semantic differences.

If full-abstraction accounts are correct, our results should essentially replicate the findings of Messenger et al. (2012). That is, both children and adults should show a main effect of Prime Construction (active vs. passive), with participants producing more passive sentences following passive than active primes, but no effect of Target Verb Type (agentpatient / theme-experiencer / experiencer-theme). If semantic-constraint accounts are correct we would expect a main effect of Target Verb Type, with participants producing more passives with agent-patient verbs (e.g. hit) than experiencer-theme verbs (e.g. see), although, 
as discussed above with regard to comprehension, the status of theme-experiencer verbs (e.g. annoy) is not clear. An additional effect of Prime Construction, with participants producing more passive sentences following passive than active primes, would suggest that - while semantically constrained - participants' knowledge is nevertheless at least partially abstract, in the sense that, minimally, they perceive some similarity between passive utterances with different nouns and verbs.

In sum, in the present paper we tested two accounts of English passive acquisition in two experiments using different methods; a forced choice comprehension study and a production priming study. Full-abstraction accounts predict no by-verb differences, except those that result from factors such as the difficulty of illustrating particular verbs in pictures or animations, and that should therefore apply equally to passives and actives. In contrast, semantic-constraint accounts predict that, across both studies, participants should show a larger decrement in passive versus active performance for experiencer-theme verbs (e.g. see) than agent-patient verbs (e.g. hit) and experiencer-theme verbs (e.g. see)

\section{Experiment 1: Forced-choice comprehension}

Method

Participants. The participants were 60 children aged 4-6 years old $(4 ; 4-6 ; 3, M=5 ; 2)$ and 60 adults aged 18-25. The children were recruited from primary schools and nurseries in the North West of England and the adults were all undergraduate students at the University of Liverpool. All participants were monolingual speakers of English and had no known language impairments.

Test items. The verbs used were 12 agent-patient (agent-patient) verbs (e.g. hug), 12 theme-experiencer (theme-experiencer) verbs (e.g. annoy) and 12 experiencer-theme (experiencer-theme) verbs (e.g. see); all 18 verbs used by Messenger et al. (2012) were included in our set. Verbs were divided into 2 lists of 18 verbs, each containing 6 verbs of each type, 3 of which were also used by Messenger et al. Details of the verbs used in each list are provided in Appendix A. Participants each heard sentences from one of the verb lists, divided across 2 days. They heard the active sentence on one day and the passive on the other for each verb. Half of the sentences on each day were active and half passive. Two versions of each list were created so that half of the participants heard each verb in a passive sentence on the first day and half heard it in an active sentence on the first day. Whether the correct animation appeared on the left or right of the screen was random. For half of the verbs 
(randomly selected), the correct animation on the second day remained on the same side of the screen; for the other half, the correct animation was on the opposite side. Trial orders were pseudo-randomised such that no more than three verbs of each type or three sentences of each type appeared in consecutive trials. Two random orders were created for each sublist. Half of the verbs had the same subject in their sentences on both test days, with the subject and object being switched in the sentences for the other half of the verbs on the second day. The set of verbs to which this switching was applied was different for each of the random playlists created. These counterbalancing and randomisation procedures resulted in the creation of 8 different stimulus orders.

For each verb, animations were created, using Anime Studio Pro 5.5, to depict the event. The same animation was used for both the active and passive sentences. Characters in each animation were one male and one female character from popular TV animation shows, chosen to be familiar to young children.

Procedure. Animations were presented on a computer screen, using Processing 3 (www.processing.org). Participants were shown one animation, slightly above the middle of the left-hand side of the screen, accompanied by the phrase Look what's happening here. A second animation then played in the middle of the right-hand side of the screen depicting the same event but with participants reversed. This was accompanied by the phrase Oh look, now it's the other way around. To make the animations maximally distinct from each other, all animations appearing on the left of the screen depicted the active subject starting on the right of the frame, while those on the right of the screen depicted the active subject starting on the left side of the frame. The animations on the left of the screen had beige backgrounds and those on the right had white backgrounds. After watching both animations separately, participants were shown both together and heard an active or passive sentence immediately following the end of the animation. Adult participants indicated the matching animation (freeze-framed on an informative frame) by pressing a key on the keyboard as quickly as possible to give their response. Children pointed to the matching animation and the experimenter then pressed the corresponding key on their behalf. Thus, reaction time measures were recorded for adult, but not child, participants.

\section{Results}

Results were analysed in RStudio (version 1.1.442; R version 3.4.4, R Core Team, 2018). As in Messenger et al. (2012), the dependent variable for the children in our study was 
correct (1) versus incorrect (0) responses. As the dependent variable was binary, results were analysed using the glmer function of the lme4 package (version 1.1-17, Bates, Maechler, Bolker \& Walker, 2015). Predictor variables were Sentence Type (active/passive) and Verb Type (agent-patient/theme-experiencer/experiencer-theme). Treatment coding was using for both predictor variables, because our goal was to compare levels directly to one another (rather than to the grand mean; i.e. effect coding); most crucially with regard to the interaction posited by semantic-constraint accounts, i.e. the relative passive (vs. active) disadvantage for (1) experiencer-theme vs. agent-patient, (2) experiencer-theme vs. themeexperiencer and (3) agent-patient vs. theme experiencer (e.g. Singmann \& Kellen, in press). This was accomplished by running relevelled models with, first, experiencer-theme and, second, agent-patient as the reference level for verb type (active was always the reference level for Sentence Type). The child model included random intercepts for verb and participant, but all random slopes were removed to enable the model to converge (Barr, Levy, Scheepers \& Tily, 2013).

Following Ambridge et al. (2016), the dependent variable for the adults in our study was reaction time $(\mathrm{ms})$. In principle, we would have liked to use the same dependent measure for adults and children, in order to allow for direct investigation of developmental changes; but reaction-time measures are too noisy to be used reliably with children, and a binary correct/incorrect measure is too insensitive for adults who show near-ceiling performance. Note that only correct responses were included in this analysis, although the adults were performing very close to ceiling (96.3\% accuracy). Following Ratcliff (1993), reaction times greater than 1.5 SDs above the mean were removed, as were reaction times below zero (i.e. where a participant responded before hearing the verb). Following recent recommendations (e.g. Lo \& Andrews, 2015) we did not apply a nonlinear transformation to the reaction time data, as this can yield misleading conclusions (e.g. Balota, Aschenbrenner \& Yap, 2013). A zscore transformation, which does not affect the parameter estimates (or $p$ values) was applied simply for ease of interpretation of the coefficients, and to allow for potential comparison across studies. As the dependent variable for this analysis was continuous, results were analysed using the lmer function of the lme4 package. Predictor variables were the same as for the children, although this time the model converged with random slopes for both main effects and the interaction included.

For the binomial child models (correct/incorrect), we report $p$ values calculated on the basis of the $z$ distribution (output by default from the glmer function of lme4). For the continuous adult models (RT to select matching picture), we report $p$ values calculated on the 
basis of the $t$ distribution, using the Satterthwaite approximation for the effective degrees of freedom (lmerTest package; Kuznetsova, Brockhoff \& Christensen, 2017). However, for the crucial interaction predicted by semantic-constraint approaches, we also - for both the child and adult models - report $p$ values calculated using the more conservative method of model comparison via the likelihood ratio test (e.g. Barr et al., 2013).

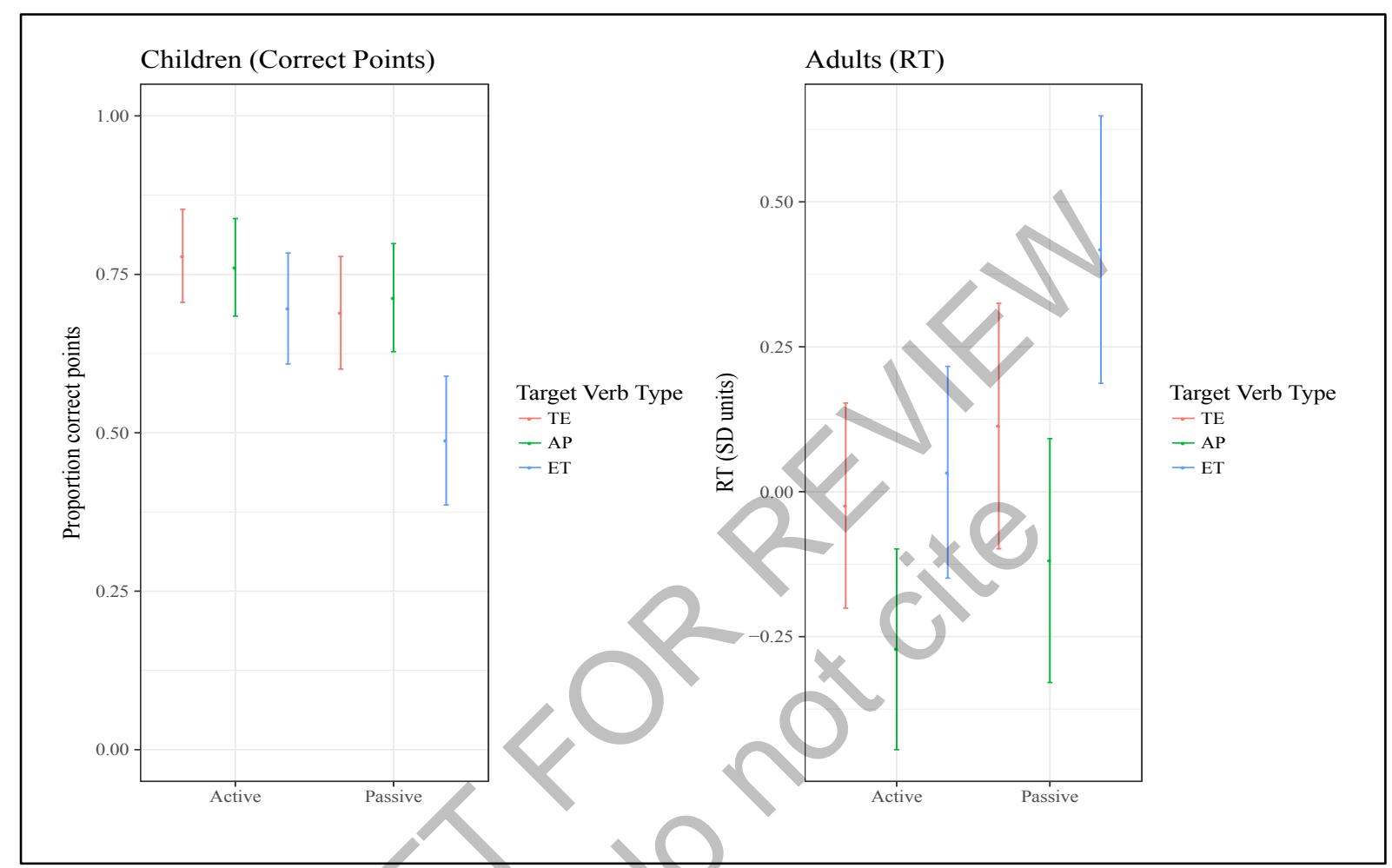

Figure 1. Comprehension study: Proportion of correct points (children) and RT for correct points (adults) for actives and passives containing theme-experiencer (e.g. annoy), agentpatient (e.g. hit) and experiencer-theme (e.g. see) verbs. [TO BE PRINTED IN COLOUR]

Figure 1 shows the mean proportion of child points to the matching picture, and the mean adult reaction time to select the matching picture, in each case broken down by Sentence Type (active/passive) and Verb Type (agent-patient / theme-experiencer / experiencer-theme). The values shown are estimated marginal means (calculated using the emmeans package for R) which correct for unbalanced cells caused by missing data.

\begin{tabular}{|lccccc|}
\hline 1a) Experiencer theme (reference level) vs AP / TE & & & & & \\
Factor & $\mathbf{M}$ & $\mathbf{S E}$ & $\mathbf{z}$ & $\mathbf{p ~ ( z )}$ & \\
(Intercept) & 0.83 & 0.21 & 3.92 & $8.78 \mathrm{E}-05$ & $* * *$ \\
Sentence $=$ Passive (vs Active) & -0.88 & 0.17 & -5.31 & $1.08 \mathrm{E}-07$ & $* * *$ \\
Verb Type $=$ AP (vs ET) & 0.33 & 0.27 & 1.24 & 0.21585 & \\
Verb Type $=$ TE (vs ET) & 0.43 & 0.27 & 1.62 & 0.10629 & \\
\hline
\end{tabular}




\begin{tabular}{|c|c|c|c|c|c|}
\hline Sentence $=$ Passive $x$ Verb Type $=$ AP $($ vs ET $)$ & 0.63 & 0.24 & 2.62 & 0.00875 & $* *$ \\
\hline Sentence $=$ Passive $\mathrm{x}$ Verb Type $=$ TE $($ vs ET $)$ & 0.41 & 0.24 & 1.72 & 0.08566 & \\
\hline \multicolumn{6}{|l|}{ 1b) Agent-patient (reference level) vs ET / TE } \\
\hline Factor & M & SE & $\mathbf{z}$ & $\mathbf{p}(\mathbf{z})$ & \\
\hline (Intercept) & 1.16 & 0.22 & 5.36 & $8.28 \mathrm{E}-08$ & $* * *$ \\
\hline Sentence $=$ Passive $($ vs Active $)$ & -0.25 & 0.18 & -1.41 & 0.15749 & \\
\hline Verb Type $=$ ET $($ vs AP $)$ & -0.33 & 0.27 & -1.24 & 0.2159 & \\
\hline Verb Type = TE (vs AP) & 0.10 & 0.27 & 0.38 & 0.70521 & \\
\hline Sentence $=$ Passive $\mathrm{x}$ Verb Type $=\mathrm{ET}($ vs AP $)$ & -0.63 & 0.24 & -2.62 & 0.00875 & $* *$ \\
\hline Sentence $=$ Passive $\mathrm{x}$ Verb Type $=\mathrm{TE}(\mathrm{vs}$ AP $)$ & -0.22 & 0.25 & -0.87 & 0.38233 & \\
\hline 1c) Model comparison & Chi & df & p (Chi) & & \\
\hline \multicolumn{6}{|l|}{ Model without interaction } \\
\hline Model with interaction & 7.14 & 2.00 & 0.02816 & & \\
\hline
\end{tabular}

Table 1. Mixed effects models for children's pointing data

Children. The models for the children's data are summarised in Table 1. The model with experiencer-theme as the reference level for Verb Type (Table 1a) revealed a significant positive interaction of Sentence Type by agent-patient (first bold row), indicating that the decrement in performance for passive vs. active sentences (the reference level), as indicated by the negative simple effect ${ }^{2}$ for sentence type, was significantly smaller for agent-patient verbs (Mean difference $=0.05, S E=0.03, Z$ ratio $=1.41$ ) than experiencer-theme verbs (Mean difference $=0.21, S E=0.04$, Z ratio $=5.39$ ), the reference level. However, the interaction of Sentence Type by theme-experiencer (second bold row) was non-significant. Thus, there is no evidence to suggest that the passive decrement was greater for theme-experiencer verbs (Mean difference $=0.09, S E=0.03, Z$ ratio $=2.60$ ) than experiencer-theme verbs (the reference category). The relevelled model with agent-patient as the reference level for Verb Type (Table 1b) found no significant interaction of Sentence Type by theme-experiencer (bold row). Thus, there is no evidence to suggest that the passive decrement was greater for theme-experiencer than agent-patient verbs (the reference category). Finally, a comparison of models with and without the crucial interaction of Sentence Type by Verb Type (Table 1c) confirmed that this interaction remained significant when using a more conservative analysis (Chi-square $=7.14, d f=2, p=0.028)$

\footnotetext{
${ }^{2}$ When treatment contrasts are used in a model with interactions, a simple effect (here Verb Type or Sentence Type) is "not what is commonly understood as a main effect" (Singmann \& Kellen, in press), and should not be interpreted without reference to the interaction. This is not a problem for our present purposes, since the theoretical predictions under investigation relate to the interaction of Sentence Type by Verb Type.
} 
In summary, the children's data show that the comprehension decrement associated with passive (vs. active) sentences was greatest for experiencer-theme verbs (e.g. see), and smallest for agent-patient verbs (e.g. hit), with theme-experiencer verbs (e.g. annoy) intermediate, and significantly different to neither.

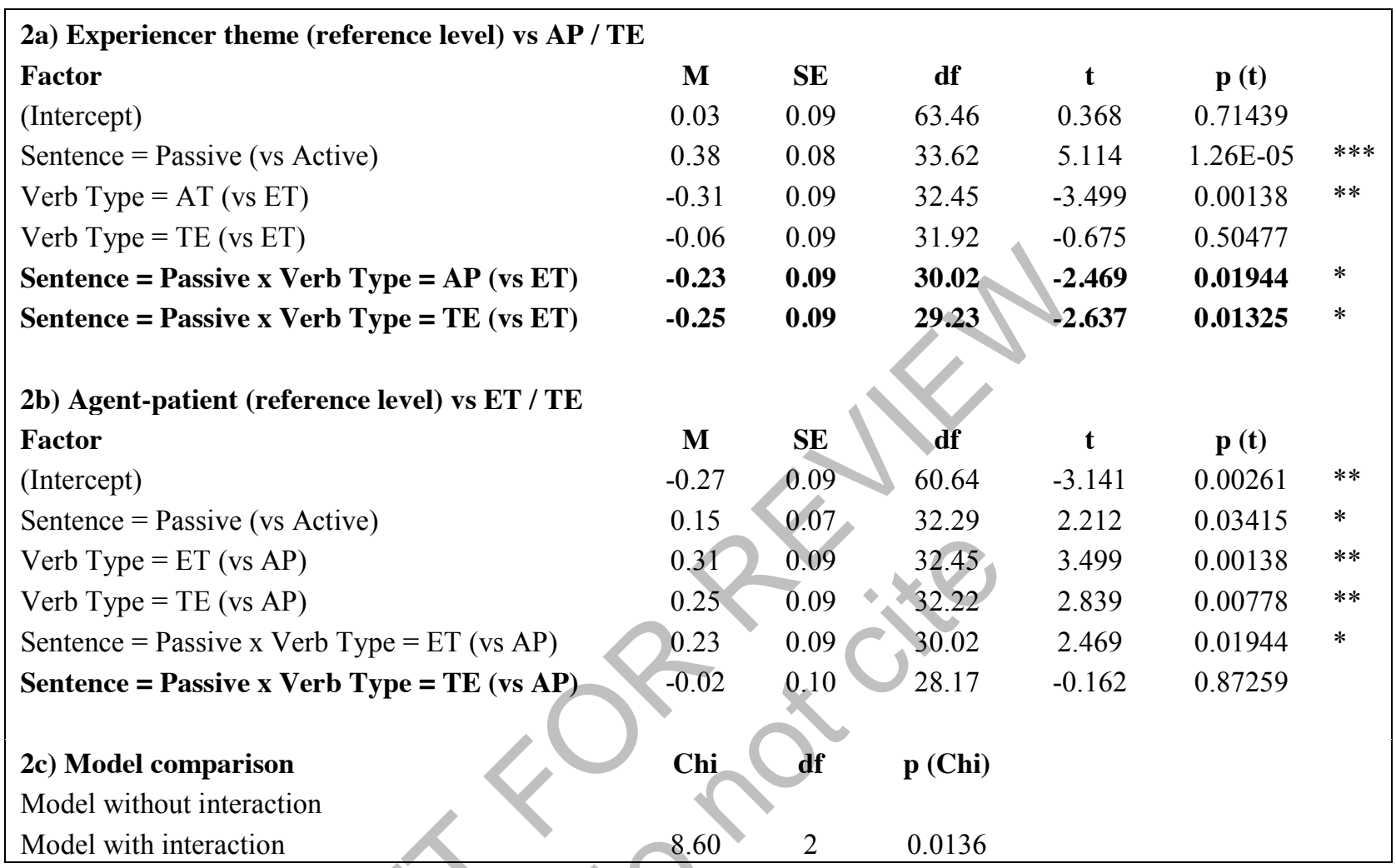

Table 2. Mixed effects models for adults' reaction time data. 
Adults. The models for adults' data are summarised in Table 2. The model with experiencer-theme as the reference level for Verb Type (Table 2a) revealed a significant positive interaction of Sentence Type by both agent-patient (first bold row) and themeexperiencer (second bold row). Thus, the decrement in performance (increased RT) for passive vs. active sentences (the reference level) - as indicated by the positive simple effect for sentence type - was significantly smaller for both agent-patient (Mean difference $=0.15$ $\mathrm{SD}$ units, $S E=0.06$, tratio $=2.21)$ and theme-experiencer verbs (Mean difference $=0.14$, $S E=0.07, t$ ratio $=1.89)$ than for experiencer-theme verbs (Mean difference $=0.38, S E=0.08, t$ ratio $=5.10)$, the reference level. The relevelled model (Table $2 \mathrm{~b})$ revealed that themeexperiencer and agent-patient verbs did not differ significantly with regard to the extent of passive decrement (i.e. the interaction in the bold row was not significant). Finally, a comparison of models with and without the crucial interaction of Sentence Type by Verb Type (Table 2c) confirmed that this interaction remained significant when using a more conservative analysis (Chi-square $=8.60, d f=2, p=0.014$ ).

In summary, the adults' RT data show that the comprehension decrement associated with passive (vs. active) sentences was greatest for experiencer-theme verbs (e.g. see), and smallest for agent-patient verbs (e.g. hit) and theme-experiencer verbs (e.g. annoy), which showed very similar patterns of performance.

Discussion. In general, the patterns displayed by children and adults were very similar, despite the use of different dependent measures: respectively, the binary measure of correct/incorrect picture choice and the continuous measure of RT to select the correct picture. Both children and adults showed a significantly smaller passive (vs. active) decrement for agent-patient verbs (e.g. hit) than experiencer-theme verbs (e.g. see). A difference was seen, however, with theme-experiencer verbs (e.g. annoy) which, in terms of passive decrement, patterned almost identically to agent-patient verbs for adults, but were intermediate between the other two verb types for children. One possible explanation is that agent-patient and theme-experiencer verbs in principle show similar passive performance, but - for children - this pattern is obscured by the fact that the latter are somewhat harder to recognise in pictures/animations than the former (Messenger et al., 2012), a difficulty that has disappeared by adulthood. Regardless of the precise status of theme-experiencer verbs, the fact that both children and adults show a greater passive comprehension decrement for experiencer-theme than agent-patient verbs is very difficult to explain under full-abstraction accounts, but consistent with semantic-constraint accounts. Furthermore, the fact that both 
children and adults showed this pattern suggests that a semantically-constrained passive construction is not merely a childhood stepping stone to a semantics-free adult passive construction. Rather, the passive construction is subject to a semantic constraint for both children and adults.

Although these findings would appear to constitute preliminary support for semantic constraint accounts, the research team that is probably the leading current advocate of the position that "syntactic representations do not contain semantic information" (Branigan \& Pickering, 2017: 8) have consistently argued that syntactic priming is the most appropriate method for investigating these representations:

the representations underlying language....we suggest...can be examined directly [emphasis added] through a behavioural measure that has been used widely in psychological research to investigate the representation of a range of information types. This method is priming.

Similarly, commenting on Branigan and Pickering's (2017) target article, Ziegler, Snedeker and Wittenberg (2017: 44) conclude that "priming offers a direct window [emphasis added] onto representation". The implication is that any support for semantic-constraint over fullabstraction accounts obtained from comprehension data must be considered tentative until similar findings have been observed using a production-priming methodology.

\section{Experiment 2: Production priming}

In order to address this issue, we ran a production priming study that closely follows Messenger et al. (2012) but with a crucial difference: while Messenger et al. varied the semantic type of the prime verb (agent-patient/theme-experiencer/experiencer-theme) while holding constant the semantic type of the target verb (agent-patient), we vary the semantic type of the target verb (agent-patient/theme-experiencer/experiencer-theme), while holding constant the semantic type of the prime verb (agent-patient). Thus, the present study investigates whether, when primed with a prototypical (agent-patient) passive, the proportion of passive sentences children and adults will produce varies as a function of the semantics of the target verb (agent-patient/theme-experiencer/experiencer-theme). As noted in the Introduction, this may constitute a more sensitive test of by-verb differences, since we are directly testing children's ability to produce (according to semantic-constraint accounts) 
maximally difficult experiencer-theme passives, as opposed to simply the ability of experiencer-theme passives to prime) relatively easy agent-patient passives.

If full-abstraction accounts are correct, our results should essentially replicate the findings of Messenger et al. (2012). That is, both children and adults should show a main effect of Prime Construction (active vs. passive), with participants producing more passive sentences following passive than active primes, but no effect of Target Verb Type (agentpatient / theme-experiencer / experiencer-theme). If semantic-constraint accounts are correct we would expect a main effect of Target Verb Type, with participants producing more passives with agent-patient verbs (e.g. hit) than experiencer-theme verbs (e.g. see); although as both discussed in the Introduction and observed in the present Study 1, the status of themeexperiencer verbs (e.g. annoy) remains an unresolved issue. An additional effect of Prime Construction would suggest that participants' representation of the passive is nevertheless at least partially abstract, in the sense that, minimally, they perceive some similarity between passive utterances with different nouns and verbs. We are agnostic as to whether we will see an interaction between Prime Construction and Target Verb Type, as neither account has any reason to predict that any observed effect of Target Verb Type will differ following Active versus Passive primes.

\section{Method}

Participants. The participants were 60 children aged $4-6$ years old $(4 ; 2-6 ; 5, M=5 ; 6)$ and 60 adults aged 19-24. The children were recruited from primary schools and nurseries in the North West of England and the adults were all undergraduate students at the University of Liverpool. All participants were monolingual speakers of English and had no known language impairments. After testing, 25 children and 6 adults were excluded for producing no correct passive utterances. Although, intuitively, excluding almost half of the child participants feels problematic, their inclusion incurs a substantial cost (convergence failure of the statistical model) for zero gain: given the use of a binomial dependent measure (correct passive $=1$, correct active $=0$ ), these participants contribute exactly zero variance to the model, and so have no effect on the outcome.

Test items. Prime verbs consisted of 24 basic agent-patient (agent-patient) verbs (e.g. $h u g$ ). Target verbs were the same verbs used in Experiment 1. All prime and target verbs are given in Appendix B. Sixteen different playlists were created, each of 36 trials. Prime sentences used 18 different agent-patient verbs, each of which appeared in both an active and 
a passive sentence, on separate trials. The remaining 6 agent-patient verbs were used as targets, along with 6 each of the theme-experiencer and experiencer-theme verbs. Participants in each action were one male and one female character from popular TV animation shows, chosen to be familiar to young children. Playlists were pseudo-randomised such that no more than 2 sentences of the same type (active/passive) or two verbs of the same type (agentpatient/theme-experiencer/experiencer-theme) appeared in a row. Active and passive sentences containing the same verb were never used in consecutive trials. The prime sentence always contained different participants to the target sentence, in order to minimise lexical overlap.

For each prime and target verb, animations were created, using Anime Studio Pro 5.5, to depict the action. The same animation was used for both the active and passive versions of prime and target sentences.

Procedure. Syntactic priming was used to encourage experimental participants to produce passive sentences. Experimenter 1 took turns with the participant to describe animations presented on a computer screen, using Processing 3 (www.processing.org). A second experimenter, who was unable to see the screen, gave 'clue words' (the prime/target verbs) to Experimenter 1 and the participant. Experimenter 2 noted down participants' responses, although sessions were also audio-recorded, using Audacity, as a backup. Following Rowland, Chang, Ambridge, Pine and Lieven (2012), we used a 'bingo game' to motivate the participants to produce responses. For each sentence produced by Experimenter 1 or the participant, Experimenter 2 looked for a bingo card that matched the sentence. In fact, Experimenter 2 had all of the bingo cards, but the game was fixed so that the participant always won the game. As the playlists were long, they were divided into 4 'games' of 9 trials, with participants requiring 6 bingo cards to win. Before starting, the game was introduced to participants with three practice trials, using verbs that were not included in the experiment proper, in active locative sentences (e.g. Homer poured water into the cup).

\section{Results}

Participants' responses were coded for sentence type, irrespective of prime condition: correct active, correct (full) passive, incorrect active (with participants reversed), incorrect (full) passive (with participants reversed), other use of the verb, and excluded (target verb not used/no response). A response was coded as a correct active if it was an accurate description of the event, and contained both a subject and direct object with the appropriate role 
(agent/patient/theme/experiencer) and the target verb. A response was coded as a correct passive if it was an accurate description of the event, and contained both a subject and object with the appropriate role (agent/patient/theme/experiencer), an auxiliary verb (get or be), the target verb and the preposition by. These criteria are similar to those used by Messenger et al. (2012), with the exceptions that (i) participants in the current study were required to use the target verb, and (ii) the range of semantic roles was more varied, as we used agent-patient, experiencer-theme and theme-experiencer verbs as targets, whereas Messenger et al. used only agent-patient verbs as targets. Table 3 shows the frequency of each response type for adults and children, both before and after the exclusion of participants who produced no correct passives.

\begin{tabular}{|lrrrrr|} 
& \multicolumn{2}{c}{ Before exclusions } & & \multicolumn{2}{c|}{ After exclusions } \\
\cline { 2 - 6 } & Children & Adults & & Children & Adults \\
Correct Active & 1355 & 1544 & 781 & 1345 \\
Correct Passive & 133 & 424 & 133 & 424 \\
Incorrect Active & 53 & 41 & 35 & 37 \\
Incorrect Passive & 6 & 14 & 5 & 14 \\
Other use of target verb & 136 & 80 & 75 & 72 \\
Excluded (no use of target verb) & 477 & 57 & 267 & 52 \\
\hline
\end{tabular}

Table 3. Categorisation of responses by age group, before and after excluding participants who produced no correct passives

We followed the same general analysis strategy as for the binomial (child) comprehension data in Study 1. The dependent variable was coded as correct active (0) or correct passive, with all other responses excluded. Predictor variables were Age Group (adult/child), Prime Construction (active/passive) and Target Verb Type (agent-patient / theme-experiencer / experiencer-theme). All models included random intercepts, but random slopes could not be added without causing convergence failure. As for Study 1, all means reported are estimated marginal means.

The results of the production priming study are summarised in Figure 2, and the statistical models in Table 4. As a full model (Table 4a) revealed no significant interactions (the same is true for a revelled model with agent-patient as the reference level), we proceeded directly (Table 4b) to a model that included factors of Age (with adult as the reference level) Prime Construction (with active as the reference level) and Target Verb Type (with experiencer-theme as the reference level). This analysis revealed main effects of Age, with 
children producing significantly fewer passives (proportion of $M=0.12, S E=0.02$ ) than adults $(M=0.21, S E=0.02)$, and of Prime Construction, with participants producing significantly more passives - in fact, more than twice as many - after passive $(M=0.23, S E=0.02)$ than active primes $(M=0.10, S D=0.01)$. This latter finding suggests that, whether or not participants' representation of the passive construction is semantically constrained, it is nevertheless sufficiently abstract for participants to, at a minimum, perceive some similarity between passive utterances with different nouns and verbs. Furthermore, although a null finding can never be taken as positive evidence of a null effect (e.g. Dienes, 2014), the lack of a significant interaction between Age and Prime Construction means that we have no evidence to suggest that the "abstractness" of participants' passive representations - whatever precisely we mean by this - changes as a function of development.

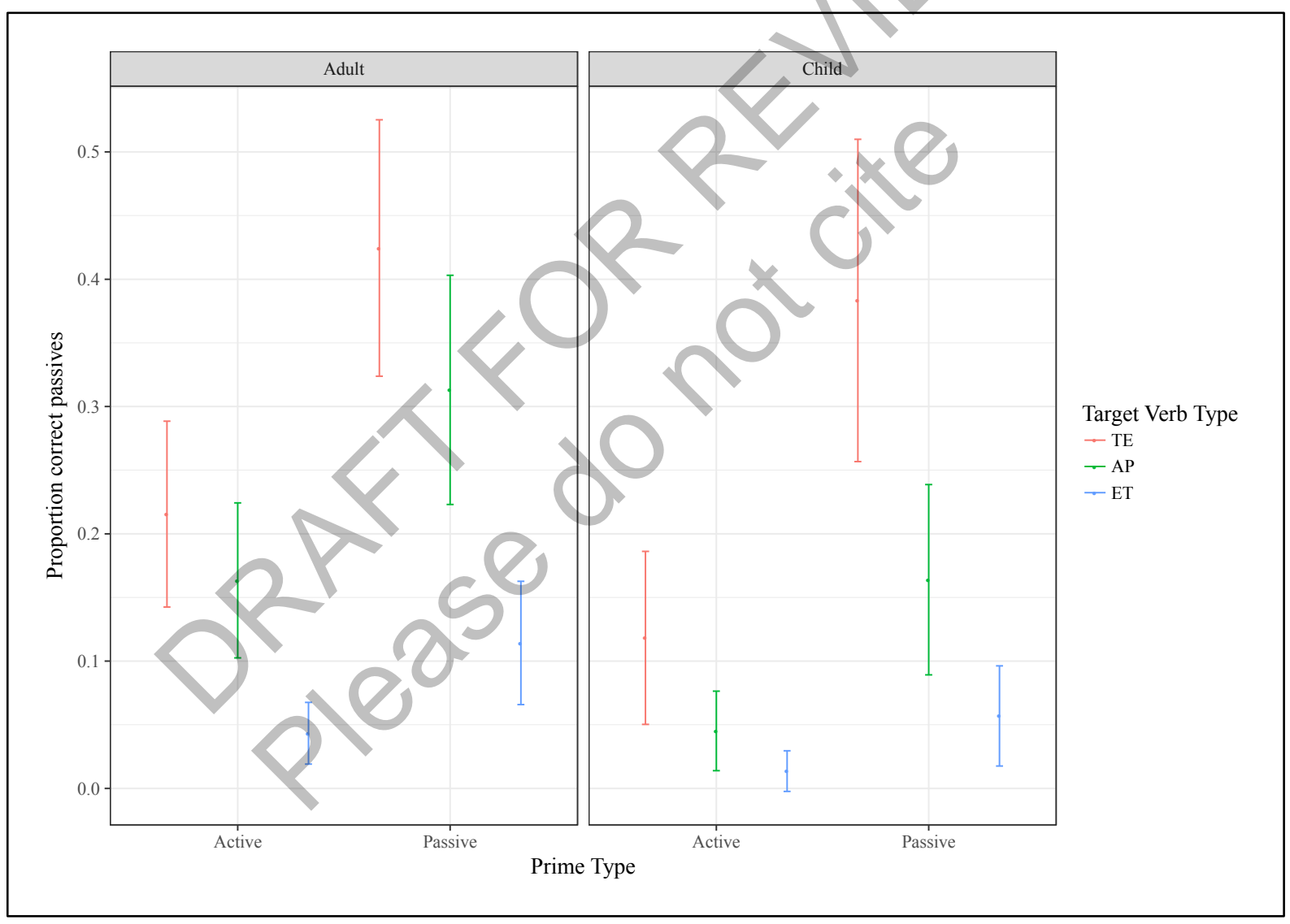

Figure 2. Priming study: Adults' and children's proportion of correct passives (vs correct actives) containing theme-experiencer (e.g. annoy), agent-patient (e.g. hit) and experiencertheme (e.g. see) target verbs following active and passive prime sentences. [TO BE PRINTED IN COLOUR] 


\begin{tabular}{|c|c|c|c|c|c|}
\hline \multicolumn{6}{|c|}{ 4a) All main effects and interactions included } \\
\hline Factor & $\mathbf{M}$ & $\mathbf{S E}$ & $\mathbf{z}$ & $\mathbf{p}(\mathbf{z})$ & \\
\hline (Intercept) & -3.09 & 0.30 & -10.37 & $2.00 \mathrm{E}-16$ & $* * *$ \\
\hline Age $=$ Child (vs Adult) & -1.20 & 0.66 & -1.84 & 0.066579 &. \\
\hline Prime $=$ Passive (vs Active) & 1.04 & 0.30 & 3.53 & 4.19E-04 & $* * *$ \\
\hline Target Verb Type $=$ AP $($ vs ET) & 1.46 & 0.33 & 4.42 & $9.75 \mathrm{E}-06$ & $* * *$ \\
\hline Target Verb Type $=$ TE $($ vs ET $)$ & 1.80 & 0.33 & 5.52 & $3.42 \mathrm{E}-08$ & $* * *$ \\
\hline Age x Prime & 0.45 & 0.72 & 0.62 & 0.535749 & \\
\hline Age $\mathrm{x}$ Target Verb Type $=$ AP & -0.21 & 0.71 & -0.30 & 0.764547 & \\
\hline Age $\mathrm{x}$ Target Verb Type $=\mathrm{TE}$ & 0.49 & 0.69 & 0.70 & 0.482741 & \\
\hline Prime $\mathrm{x}$ Target Verb Type $=$ AP & -0.20 & 0.36 & -0.55 & 0.582658 & \\
\hline Prime $\mathrm{x}$ Target Verb Type $=\mathrm{TE}$ & -0.06 & 0.35 & -0.16 & 0.873683 & \\
\hline Age $\mathrm{X}$ Prime $\mathrm{x}$ Target Type $=\mathrm{AP}$ & 0.13 & 0.83 & 0.15 & 0.879402 & \\
\hline Age $\mathrm{X}$ Prime $\mathrm{x}$ Target Type $=\mathrm{TE}$ & 0.10 & 0.81 & & 0.902204 & \\
\hline \multicolumn{6}{|c|}{ 4b) After removal of non-significant interactions - Experiencer theme (reference level) vs AP / TE } \\
\hline Factor & M & SE & $\mathbf{z}$ & $\mathbf{p}(\mathbf{z})$ & \\
\hline (Intercept) & -3.15 & 0.23 & -13.72 & $2.00 \mathrm{E}-16$ & $* * *$ \\
\hline Age $=$ Child (vs Adult) & -0.72 & 0.23 & -3.14 & 0.00168 & $* *$ \\
\hline Prime $=$ Passive $($ vs Active $)$ & 1.08 & & 9.72 & $2.00 \mathrm{E}-16$ & $* * *$ \\
\hline Target Verb Type $=\mathbf{A P}($ vs ET $)$ & 1.29 & 0.23 & 5.70 & 1.19E-08 & $* * *$ \\
\hline Target Verb Type $=$ TE $($ vs ET $)$ & & 0.23 & 8.40 & $2.00 \mathrm{E}-16$ & $* * *$ \\
\hline \multicolumn{6}{|c|}{$\begin{array}{l}\text { 4c) After removal of non-significant interactions - Agent patient (reference level) } \\
\text { vs ET/ TE }\end{array}$} \\
\hline Factor & & & $\mathbf{z}$ & $\mathbf{p}(\mathbf{z})$ & \\
\hline (Intercept) & 1.80 & 0.20 & -9.08 & $2.00 \mathrm{E}-16$ & *** \\
\hline Age $=$ Child $($ vs Adult $)$ & & 0.23 & -3.14 & 0.00168 & $* *$ \\
\hline Prime $=$ Passive $($ vs Activ & 1.08 & 0.11 & 9.72 & $2.00 \mathrm{E}-16$ & $* * *$ \\
\hline Target Verb Type $=$ ET $($ vs AP $)$ & -1.29 & 0.23 & -5.70 & $1.19 \mathrm{E}-08$ & $* * *$ \\
\hline Target Verb Type $=\mathrm{TE}(\mathrm{vs}$ AP $)$ & 0.61 & 0.20 & 2.97 & 0.00296 & $* *$ \\
\hline 4d) Model comparisons & Chi & df & p (Chi) & & \\
\hline Model with Age Group & 9.43 & 1 & 0.002139 & ** & \\
\hline Model without Prime Construction & 98.55 & 1 & $2.20 \mathrm{E}-16$ & $* * *$ & \\
\hline Model without Target Verb Type & 41.93 & 2 & $7.87 \mathrm{E}-10$ & $* * *$ & \\
\hline
\end{tabular}

Table 4. Mixed effects model for children's and adults' priming data. Experiencer theme (reference level) vs AP / TE

Crucially, the simple contrasts for Verb Type (the two bold rows in Table 4b) demonstrate that significantly more passives were produced with agent-patient verbs (e.g. hit; $M=0.18$, $S E=0.02$ ) and theme-experiencer verbs (e.g. annoy; $M=0.27, S E=0.03$ ) than with experiencertheme verbs (e.g. see; $M=0.06, S E=0.01$ ). The additional contrast in the relevelled model, with agent-patient as the reference level (bold row of Table 4c) further revealed that 
significantly more passives were produced with theme-experiencer verbs (e.g. annoy) than agent-patient verbs (e.g. hit).

\begin{tabular}{|c|c|c|c|c|c|}
\hline \multicolumn{6}{|c|}{ 5a) Experiencer theme (reference level) vs AP / TE } \\
\hline Factor & $\mathbf{M}$ & SE & $\mathbf{z}$ & $\mathbf{p}(\mathbf{z})$ & \\
\hline (Intercept) & -4.40 & 0.45 & -9.84 & $2.00 \mathrm{E}-16$ & $* * *$ \\
\hline Prime $=$ Passive (vs Active) & 1.53 & 0.24 & 6.26 & $3.96 \mathrm{E}-10$ & $* * *$ \\
\hline Target Verb Type $=$ AP $($ vs ET $)$ & 1.22 & 0.44 & 2.77 & 0.00561 & $* *$ \\
\hline Target Verb Type $=$ TE $($ vs ET $)$ & 2.38 & 0.44 & 5.40 & 6.85E-08 & $* * *$ \\
\hline \multicolumn{6}{|c|}{ 5b) Agent-patient (reference level) vs ET / TE } \\
\hline Factor & M & SE & $\mathbf{z}$ & $\mathbf{p}(\mathbf{z})$ & \\
\hline (Intercept) & -3.18 & 0.36 & -8.77 & $2.00 \mathrm{E}-16$ & $* * *$ \\
\hline Prime $=$ Passive (vs Active $)$ & 1.53 & 0.24 & 6.26 & $3.96 \mathrm{E}-10$ & $* * *$ \\
\hline Target Verb Type = ET (vs AP) & -1.22 & 0.44 & & 0.00561 & $* *$ \\
\hline Target Verb Type $=$ TE $($ vs AP $)$ & 1.16 & & & 0.00158 & $* *$ \\
\hline $\begin{array}{l}\text { 5c) Model comparison } \\
\text { Full model vs }\end{array}$ & Chi & & (Chi) & & \\
\hline Model without Prime Construction & 45.72 & & $1.36 \mathrm{E}-1$ & $* * *$ & \\
\hline Model without Target Verb Type & 23.39 & & $32 \mathrm{E}-0$ & $* * *$ & \\
\hline
\end{tabular}

Table 5. Priming analyses: children only.

\begin{tabular}{|c|c|c|c|c|c|}
\hline \multicolumn{6}{|c|}{ 6a) Experiencer theme (reference level) vs AP / TE } \\
\hline Factor & M & SE & $\mathbf{z}$ & $\mathbf{p}(\mathbf{z})$ & \\
\hline (Intercept) & -3.01 & 0.23 & -12.84 & $2.00 \mathrm{E}-16$ & *** \\
\hline Prime $=$ Passive $(\mathrm{vs} A$ & 0.94 & 0.13 & 7.42 & $1.19 \mathrm{E}-13$ & $* * *$ \\
\hline Target Verb Type $=\mathbf{A P}($ vs ET $)$ & 1.33 & 0.23 & 5.89 & 3.86E-09 & *** \\
\hline Target Verb Type $=$ TE $($ vs ET $)$ & 1.75 & 0.22 & 7.78 & 7.12E-15 & *** \\
\hline \multicolumn{6}{|c|}{ 6b) Agent-patient (reference level) vs ET / TE } \\
\hline Factor & M & SE & $\mathbf{z}$ & $\mathbf{p}(\mathbf{z})$ & \\
\hline (Intercept) & -1.68 & 0.20 & -8.27 & $2.00 \mathrm{E}-16$ & $* * *$ \\
\hline Prime $=$ Passive $($ vs Active $)$ & 0.94 & 0.13 & 7.42 & $1.19 \mathrm{E}-13$ & *** \\
\hline Target Verb Type = ET (vs AP) & -1.33 & 0.23 & -5.89 & 3.86E-09 & *** \\
\hline Target Verb Type $=$ TE $($ vs AP $)$ & 0.42 & 0.20 & 2.10 & 0.0355 & $*$ \\
\hline 6c) Model comparison & Chi & df & p (Chi) & & \\
\hline \multicolumn{6}{|l|}{ Full model vs } \\
\hline Model without Prime Construction & 56.69 & 1 & $5.11 \mathrm{E}-14$ & $* * *$ & \\
\hline Model without Target Verb Type & 39.29 & 2 & $2.95 \mathrm{E}-09$ & $* * *$ & \\
\hline
\end{tabular}

Table 6. Priming analyses: adults only. 
As shown in Table 4d, the main effects of Age, Prime Construction and Verb Type set out above were confirmed by a more-conservative model-comparison analysis using the likelihood-ratio test (implemented automatically using the dropl command in lme4).

Finally, although the full model (Table 4a) did not yield any significant interaction involving age, it seemed important (particularly given the unbalanced sample sizes for children and adults) to check whether the findings above held for each age group when analysed separately. Separate models run for children (Table 5) and adults (Table 6) revealed patterns of findings that were identical to one another, and to the all-participant analyses (Table 4).

To summarise, the findings of the production-priming study largely mirror those of the comprehension study (Study 1). Both adults and children produced significantly more passives with agent-patient verbs (e.g. hit) than experiencer-theme verbs (e.g. see). This finding is difficult to explain under full-abstraction accounts; indeed, the opposite finding the absence of by-verb-type differences in production priming (Messenger et al., 2012) - was taken as positive evidence for such accounts. These findings, like those of Study 1, are clearly consistent with semantic-constraint accounts; although a difficulty for such accounts is explaining the different behaviour of theme-experiencer verbs across the present studies. In terms of a passive (vs. active) deficit in comprehension, theme-experiencer verbs (e.g. annoy) behaved almost exactly like agent-patient verbs (e.g. hit) for adults, but were intermediate between agent-patient and experiencer-theme verbs for children. In production, for both adults and children alike, theme-experiencer verbs yielded more passives than either of the other two verb types. Possible explanations for the different performance of experiencertheme verbs across comprehension and production-priming will be considered in the General Discussion. In the meantime, the findings of the production priming study provide support for semantic-constraint over full-abstraction accounts, in demonstrating higher rates of passive production for both agent-patient and theme-experiencer than experiencer-theme verbs.

\section{General Discussion}

The aim of the present research was to investigate possible semantics-based differences in passivisability between agent-patient verbs (e.g. hit), theme-experiencer verbs (e.g. annoy) and experiencer-theme verbs (e.g. see), in order to mediate between semantic-constraint accounts, which predict the existence of such differences, and full-abstraction accounts that do not, on the basis that "syntactic representations do not contain semantic information" 
(Branigan \& Pickering, 2017: 8). Across both children and adults, and across both comprehension and production, agent-patient verbs were consistently found to be higher in passivisability than experiencer-theme verbs. The adult comprehension data, and both adult and child production data, provided evidence that theme-experiencer verbs are also higher in passivisability than experiencer-theme verbs (for child comprehension data, this comparison was not significant; $p=0.09$, n.s.).

These findings are difficult to explain under full-abstraction accounts that assume no by-verb differences in passivisability. They are clearly consistent with semantic-constraint accounts under which the "ideal" passive subject is a patient of the action/event denoted by the verb, and/or highly affected by it (e.g. Bob was hit/annoyed by Wendy; c.f., Bob was seen by Wendy). However, as this rather general definition shows, semantic constraint accounts have yet to tie down the precise verb semantics that characterise high passivisability. This presents a considerable challenge, given the somewhat different performance of themeexperiencer verbs across the present studies. The production-priming data suggest that, for both adults and children, theme-experiencer verbs are the most passivisable of all. This is consistent with the view of passive semantics laid out by Pinker et al. (1987; see also Ferreira, 1994; Ambridge et al., 2016), on the basis that passive subjects of themeexperiencer verbs are highly affected almost by definition (e.g. Bob was annoyed/scared by Wendy ... ?but, actually, he didn't notice), which is not the case for agent-patient verbs (e.g. Bob was hit/kicked by Wendy ... but, actually, he didn't notice). However, the comprehension data suggest that theme-experiencer verbs are, for adults, almost exactly on a par with agentpatient verbs in terms of passivisability. The child comprehension data are less clear, although again the patterning of theme-experiencer verbs looks more similar to the patterning of agent-patient than theme-experiencer verbs (although significantly different to neither).

Why, then, do theme-experiencer verbs appear to be more passivisable than agentpatient verbs in comprehension, but only as passivisable in comprehension? When considering possible answers to this question, we would suggest that - counter to Branigan and Pickering (2017) - no method (comprehension, production, or, indeed, grammaticality judgments) can ever offer a direct window onto participants' grammatical representations. Rather, the in-principle passivisability of different verbs must be inferred on the basis of participants' performance on different experimental tasks, each of which has its own demands and potential task strategies. The most obvious difference between production priming and comprehension is that, in the former task, although of course influenced by the prime, participants are, in effect, choosing whether or not to produce a passive construction 
(perhaps, in some cases, consciously). Presumably, they will only produce a passive if the naturalness of resulting passive sentence (a) reaches some implicit threshold and (b) is not considerably lower than that of the equivalent active sentence, which would also constitute a good description of the animation. In comprehension, the naturalness of the passive is less important; it need only be natural enough to allow for a rapid identification of the matching picture in the adult RT task, or for correct identification in the non-timed child task.

Bearing these methodological considerations in mind, it seems to us that the production-priming task yields a more sensitive measure of relative passivisability than the comprehension task, and should therefore be given more weight when we are attempting to delineate the semantics of passivisability (particularly given that our own production-priming findings mirror those of an adult free-production task; Ferriera, 1994). Thus, in our view, the true picture is that the cline of passivisability is theme-experiencer (e.g. annoy) $>$ agentpatient (e.g. hit)> experiencer-theme (e.g. see). Although this cline partially reverses the traditional distinction between "action" and "mental-state/psychological" verbs, it chimes with both Pinker et al.'s (1987) definition of the semantics of the passive as, essentially, "affectedness", and with the adult findings of Ambridge et al.(2016). Ambridge et al. found that a continuous measure of affectedness was a significantly better predictor of passive than active performance in both grammaticality judgment and timed comprehension tasks.

Whether or not this characterisation of passive semantics is entirely accurate, the findings of the present comprehension studies strongly suggest that such a constraint indeed exists, for both adults and children. At the same time, the finding that children showed a priming effect - with no evidence to suggest that it is any smaller than that observed for adults - suggests that a successful account of children's acquisition of the passive will need to incorporate aspects of both semantic-constraint and full-abstraction accounts. In other words, the dichotomy between these two approaches summarised at the start of the present article is a false one. Yes, knowledge of the passive is semantically constrained, for both adults and children. But, yes, at the same time even children's knowledge of the passive is sufficiently "abstract" to yield syntactic priming effects. What is needed then is an account that explains both the observed semantic constraint on the passive, and exactly what is entailed by an "abstract" syntactic representation of the passive that is at the same time semantically constrained. We can see three possibilities.

The first possible account maintains the position that syntactic representations do not contain semantic information, and views the types of effects observed in the present study (and Ferreira, 1994 and Ambridge et al., 2016) as mere quirks of usage (i.e. "grammar is 
grammar, and usage is usage"; Newmeyer, 2003). Under this account, the job of the grammar is to determine which strings are and are not possible sentences of English. Thus, given that all of the target passive sentences in the present studies were possible English sentences, small differences in their ease of interpretation or rates of production are irrelevant. One problem with this account is that it is untestable, as it effectively renders all existing and future experimental findings irrelevant to the question of the nature of speakers' syntactic representations. A second problem is that the same semantic feature that is associated with slower and less accurate interpretation/production for the present passive sentences - i.e. affectedness - also offers an explanation of why some verbs cannot be passivised at all (e.g. *\$5 was cost by the book; *Five people are slept by this tent; Pinker et al., 1987). Thus, semantic affectedness affects not merely usage, but which passives are and are not possible English sentences; information that must be represented somehow in the grammar.

The second possible account holds that the passive is represented as a semantic prototype construction (e.g. Maratsos et al., 1987; Ambridge et al., 2016; see Ibbotson, Theakston, Lieven \& Tomasello, 2012 for a similar account of the English transitive construction, and Ibbotson \& Tomasello, 2009, for a review of prototype accounts in language acquisition more generally). On this view, learners build an increasingly abstract passive construction by schematising and analogising across concrete passive utterances that they hear in the input (e.g. Tomasello, 2003). The adult endpoint is a passive construction [SUBJECT] BE/GET [VERB]ed/en by [OBJECT] that is fully-abstract in the sense that it can be used to comprehend and generate passive utterances with any verb (except highly nonactional verbs like cost and sleep), but at the same time is semantically constrained: the naturalness of the resulting passive (and hence its ease of comprehension and its production probability) varies continuously as a function of the extent to which the semantics of the particular verb overlap with the semantics of the VERB slot, defined as subject-affectedness (in the sense of Pinker et al., 1987; Ambridge et al., 2016). Where do the semantics of the VERB slot come from? They are simply a frequency-weighted average of the semantics of all the individual verbs that have appeared in that slot in the input utterances that gave rise to the construction.

A problem for the semantic construction prototype account is that, as has long been recognised in the non-linguistic categorisation literature (see Love, 2013, for a review), this averaging process means that prototype models cannot represent categories whose members are opposites along the dimension that defines category membership. For example, a category whose members are either black or white cannot be represented by a prototype, since the 
averaging process would yield a grey prototype that does not capture the relevant property (i.e. colour) of any of its members. In just the same way, a semantic prototype for the English passive cannot represent both passives of the form THEME-VERB-EXPERIENCER (e.g. Bob frightened Wendy) and EXPERIENCER-VERB-THEME (e.g. Bob feared Wendy); i.e. passives that are opposites in terms of the mapping between word order and semantic roles. While the averaging process might work well enough for the VERB slot, it is hopeless for the SUBJECT and OBJECT slots. The prototype passive SUBJECT, under this account, would be neither a THEME nor an EXPERIENCER but - impossibly - something in between.

A third possible account of the English passive is an exemplar model, under which the passive construction is not represented as a stored abstraction at all. Rather, speakers simply store all the passive utterances that they hear (although imperfectly, and with considerable forgetting), and produce and comprehend new passive utterances by on-the-fly analogy across all of these stored utterances. Although exemplar accounts have made few inroads into theories of language acquisition ${ }^{3}$, they are well established in the non-linguistic categorisation literature, precisely because they overcome the averaging problem that is fatal for prototype models. Indeed, in this literature, it is generally well accepted that "by and large, exemplar models can mimic all the behaviours of prototype models, but the opposite is not true" (Love, 2013: 248). For example, a finding that is sometimes taken as support for prototype models (including - in a linguistic context - by Ibbotson et al., 2012) is that participants often "recognise" previously-unseen exemplars that are close to the putative prototype, while failing to recognise previously-seen exemplars that are distant from this prototype. However, exemplar models simulate this finding, too, because a previously-unseen exemplar that is close to a putative prototype is, by the very definition of a prototype, similar to a large number of previously-seen exemplars. Thus participants "recognise" the unseen but prototypical example by generalising across these exemplars. Furthermore, when prototypicality is held constant, participants show an advantage for previously-seen items (e.g. Zaki, Nosofsky, Stanton \& Cohen, 2003); a finding that can be explained by exemplar but not prototype - models.

In just the same way then, an exemplar model of passive acquisition can explain the present findings of a semantic constraint on the passive construction. If the majority of stored passive utterances in the input describe an event in which the passive subject is highly

\footnotetext{
${ }^{3}$ One exception is the domain of phonetics and phonology. This exception is telling: because researchers in this domain are sensitive to the need to account for a high degree of variability in production of "the same" word by speakers of different genders, with different accents and so on (e.g. Labov, 1963), they generally recognise the need to eschew averaging prototype models in favour of models that retain considerable phonetic detail.
} 
affected, then comprehension and production of passives will be facilitated when the target passive in an experimental study also has these properties, thus facilitating the process of analogy. Indeed, an exemplar model can, in principle, explain not just the syntactic priming effects observed in the present study (and Messenger et al., 2012), but also those observed across a wide range of previous studies with adults and children. A prime sentence such as The vase was broken by the hammer activates in memory not an abstract representation of the passive, but stored concrete exemplars that meet some threshold for both surface similarity (phonological and suprasegmental; i.e. length and stress patterns) and semantic similarity, both passive (e.g. The man got run over by a bus; The window was smashed by a ball) and active (e.g. The man broke the vase). When generating a subsequent utterance, the speaker does so by means of on-the-fly analogy across relevant stored examples, just as when generating any utterance. The only difference is that a number of concrete passive exemplars, having been recently activated by the prime, are more available for retrieval than they would otherwise have been.

An exemplar account of priming can explain a number of findings that are problematic for abstraction-based accounts; both semantics-free accounts such as those posited by Branigan and Pickering (2017) and semantic-prototype accounts such as those posited by Ambridge et al. (2016) and Ibbotson et al. (2012).

First, a very reliable finding (see the metâ-analysis of Mahowald, James, Futrell \& Gibson, 2016) is that the priming effect is boosted if lexical material is shared between the prime and the target (e.g. between The vase was broken by the ball and The window was broken by the hammer, or even - as in Savage et al., 2003 - between It got pushed by it and It got broken by it). Abstraction-based accounts can explain this "lexical boost" only by positing some form of add-on, such as "a representation that encodes a binding between constituent structure and the lemma (syntactic component) of the lexical entry for the head" (Branigan \& Pickering, 2017:12) or "short-term activation of explicit memory traces" (Rowland et al., 2012: 53). Such add-ons have no independent motivation; they are posited solely to explain the lexical boost. In contrast, an exemplar account explains the lexical boost naturally, with no need for additional assumptions: the prime preferentially activates stored exemplars with which it shares surface (lexical, phonological, suprasegmental) and semantic overlap, with these exemplars therefore more available for use via analogy in subsequent production. In other words, the greater the lexical overlap between prime and target, the greater the contribution of the prime to the process of on-the-fly analogy that generates the target. An exemplar account also explains why the lexical boost appears to increase with 
development (Rowland et al., 2012): the more exemplars have been stored in memory, the greater the probability of overlap between the prime and similar stored exemplars that also contribute to this process of analogy.

Second, an exemplar account naturally explains why priming is seen in cases where there is substantial lexical overlap between the prime and the target, but only debatable overlap in terms of abstract syntax. Bock and Loebell (1990) famously showed that passive sentences such as The construction worker was hit by the bulldozer prime intransitive locative (i.e. non-passive) sentences such as The 747 was landing by the airport's control tower. This is entirely expected on an exemplar account, on the basis of overlap between these utterances in terms of overlap in lexical/phonological material (e.g. Ziegler, Goldberg \& Snedeker, 2018) and suprasegmental properties such as the length and stress patterns of the sentences. It is entirely unexpected on a standard linguistic analysis which views these two abstract constructions as having very different underlying syntactic structure. Again, then, the abstraction-based approach favoured by, amongst others, Branigan and Pickering (2017: 9) requires a special workaround; here the assumption that "abstract syntactic representations.... are shallow and monostratal" (i.e. [NOUN PHRASE] [VERB PHRASE] by [NOUN PHRASE], as opposed to [SUBJECT] BE [VERB] by [OBJECT]). This solution is unsatisfactory, as it fails to account for the important semantic differences between the two constructions. For example, in The worker was hit by the boss (passive) and The worker was sitting by the tree (intransitive), 'the worker' is playing very different semantic roles (PATIENT and ACTOR respectively), which is precisely why traditional syntactic theories posit different syntactic structures in the first place.

Third, an exemplar account naturally explains why priming is boosted if the prime and target share not only lexical overlap, but also overlap in the ordering of their semantic roles. Chang, Bock and Goldberg (2003) found that if syntactic structure (in the monostratal sense) is held constant, priming is boosted if the prime and target overlap in terms of their semantic roles. For example, a target sentence such as The farmer heaped straw [THEME] onto the wagon [LOCATION] is better primed by another THEME-LOCATION sentence (e.g. The maid rubbed polish onto the table) than by a similar LOCATION-THEME sentence (e.g. The maid rubbed the table with polish). Again, this is entirely expected on an exemplar account under which the prime preferentially activates stored exemplars in proportion to the degree of both phonological and semantic overlap. And, again, it is highly problematic for an abstraction-based account. Branigan and Pickering (2017: 10) suggest that these findings "could have reflected a tendency to repeatedly assign thematic roles (e.g. Location) to 
grammatical functions (e.g. direct object) or to word-order positions (e.g. immediately following the verb)". But this tendency is not incorporated into their theoretical model; and, indeed, overlap in terms of particular semantics and particular word-order positions is more characteristic of an exemplar account than one based solely on overlap of abstract syntactic structure.

In summary, an exemplar account of the acquisition of the English passive - and of syntactic priming more generally - holds a number of potential advantages. It also faces two problems. The first is the prima facia implausibility of storing tens of millions of individual sentence exemplars (which is presumably the reason why exemplar accounts have made few inroads into theories of language acquisition). However, experimental findings indicate that memory has a far greater capacity than we might intuitively suppose (and, in fact, may not have a finite capacity at all). For example, Standing (1973) found that participants shown 10,000 photographs could, two days later, subsequently categorise a randomly-chosen subset of 160 as seen or unseen with an average success rate of $83 \%$. A second problem for exemplar accounts lies with specifying "similarity"; the criteria that weights stored exemplars in the process of analogy. Although we have suggested a number of dimensions along which different passive exemplars can be similar (overlap in terms of lexical items, phonology, semantics, sentence length and stress patterns) the relative contribution of these (and presumably additional) factors can be tied down only with some form of computational modelling. This therefore should be a goal of future research. That said, it is important to bear in mind that this problem is also shared by prototype accounts, which also require analogy across stored exemplars, and differ only in that the product of this analogy is stored as a prototype.

In conclusion, whether or not these more speculative suggestions turn out to be correct, the present findings have provided evidence that, for both children and adults, knowledge of the passive is both abstract - in the sense that speakers recognise similarity across different exemplars in a way that yields syntactic priming effects - and semantically constrained, in that theme-experiencer and agent-patient verbs yield higher rates of passive comprehension and production - relative to actives - than do experiencer-theme verbs. Any future account of the acquisition of the passive, or of the acquisition and representation of syntax more generally, will need to account for these findings. 


\section{Acknowledgements}

We would also like to thank the schools, teachers, parents and children who made this research possible, and the undergraduate students who assisted with data collection.

Funding: Amy Bidgood, Caroline Rowland, Julian Pine and Ben Ambridge are, respectively, Research Associate and Professor (x3) in the ESRC International Centre for Language and Communicative Development (LuCiD) at the University of Liverpool. The support of the Economic and Social Research Council [ES/L008955/1] is gratefully acknowledged. This work was also supported by Grant RPG-158 from the Leverhulme Trust. 


\section{References}

Ambridge, B., Bidgood, A., Pine, J.M., Rowland, C.F. \& Freudenthal, D. (2016). Is passive syntax semantically constrained? Evidence from adult grammaticality judgment and comprehension studies. Cognitive Science, 40(6) 1435-1459.

Balota, D. A., Aschenbrenner, A. J., and Yap, M. J. (2013). Additive effects of word frequency and stimulus quality: the influence of trial history and data transformations. Journal of Experimental Psychology: Learning Memory and Cognition. 39, 1563-1571.

Barr, D. J., Levy, R., Scheepers, C., \& Tily, H. J. (2013). Random effects structure for confirmatory hypothesis testing: Keep it maximal. Journal of Memory and Language, $68(3), 255-278$.

Bates, D., Maechler, M., Bolker, B., \& Walker, S. (2015). lme4: Linear mixed-effects models using Eigen and s4. R package version 1.1-17. http://cran.r-project.org/package=lme4.

Bencini, G. M. L., \& Valian, V. V. (2008). Abstract sentence representations in 3-year-olds: Evidence from language production and comprehension. Journal of Memory and Language, 59(1), 97-113.

Bock, J. K. (1986). Syntactic persistence in language production. Cognitive Psychology, $18(3), 355-387$.

Bock, K., \& Loebell, H. (1990). Framing sentences. Cognition, 35(1), 1-39.

Bock, K., Loebell, H., \& Morey, R. (1992). From conceptual roles to structural relations: Bridging the syntactic cleft. Psychological Review, 99(1), 150-171.

Branigan, H. (2007). Syntactic priming. Language and Linguistics Compass, 1(1-2), 1-16.

Branigan, H. P., \& Pickering, M. J. (2017). An experimental approach to linguistic representation. Behavioral and Brain Sciences, 40.

Branigan, H., Pickering, M. J., Liversedge, S. P., Stewart, A. J., \& Urbach, T. P. (1995). Syntactic priming: Investigating the mental representation of language. Journal of Psycholinguistic Research, 24(6), 489-506.

Chang, F., Bock, K., \& Goldberg, A. E. (2003). Can thematic roles leave traces of their places? Cognition, 90(1), 29-49.

Chomsky, N. (1957). Syntactic structures. The Hague: Mouton.

Chomsky, N. (1993). A minimalist program for linguistic theory. In K. Hale \& S. J. Keyser (Eds.), The view from building 20 (pp. 1-52). Cambridge, MA: MIT Press. 
Coyle, J. M., \& Kaschak, M. P. (2008). Patterns of experience with verbs affect long-term cumulative structural priming. Psychonomic Bulletin \& Review, 15(5), 867-970.

Dabrowska, E., \& Street, J. (2006). Individual differences in language attainment: Comprehension of passive sentences by native and non-native English speakers. Language Sciences, 28(6), 604-615.

Dienes, Z. (2014). Using Bayes to get the most out of non-significant results. Frontiers in Psychology, 5, 781.

Ferreira, F. (1994). Choice of passive voice is affected by verb type and animacy. Journal of Memory and Language, 33, 715-715.

Fox, D., \& Grodzinsky, Y. (1998). Children's passive: A view from the by-phrase. Linguistic Inquiry, 33(2), 311-332.

Gertner, Y., Fisher, C., \& Eisengart, J. (2006). Learning words and rules: Abstract knowledge of word order in early sentence comprehension. Psychological Science, 17(8), 684-691.

Gordon, P. \& Chaftez, J. (1990). Verb-based versus class-based accounts of actionality effects in children's comprehension of passives. Cognition, 36(3), 227-254.

Hirsch, C., \& Wexler, K. (2006). Children's passives and their resulting interpretation. In K. Deen, J. Nomura, B. Schulz, \& B. Schwartz (Eds.), The proceedings of the inaugural conference on generative approaches to language acquisition - North America (pp. 125-136). University of Connecticut occasional papers in linguistics 4.

Huttenlocher, J., Vasilyeva, M., \& Shimpi, P. (2004). Syntactic priming in young children. Journal of Memory and Language, 50(2), 185-195.

Ibbotson, P., Theakston, A. L., Lieven, E. V., \& Tomasello, M. (2012). Semantics of the transitive construction: prototype effects and developmental comparisons. Cognitive Science, 36(7), 1268-1288.

Ibbotson, P., \& Tomasello, M. (2009). Prototype constructions in early language acquisition. Language and Cognition, 1(1), 29-85.

Israel, M., Johnson, C., \& Brooks, P. J. (2000). From states to events: The acquisition of English passive participles. Cognitive Linguistics, 11(1-2), 103-129.

Kuznetsova A., Brockhoff P.B. and Christensen R.H.B. (2017). lmerTest Package: Tests in Linear Mixed Effects Models. Journal of Statistical Software, 82(13), 1-26.

Labov, W. (1963). The social motivation of a sound change. Word, 19(3), 273-309.

Lo, S., \& Andrews, S. (2015). To transform or not to transform: Using generalised linear mixed models to analyse reaction time data. Frontiers in Psychology, 6, 1171. 
Love, B.C. (2013). Categorization. In K.N. Ochsner and S.M. Kosslyn (Eds.). Oxford Handbook of Cognitive Neuroscience (pp.342-358). Oxford: Oxford University Press.

Mahowald, K., James, A., Futrell, R., \& Gibson, E. (2016). A meta-analysis of syntactic priming in language production. Journal of Memory and Language, 91, 5-27.

Maratsos, M., Fox, D., Becker, J., \& Chalkey, M. (1985). Semantic restrictions on children's passives. Cognition, 19(2), 167-191.

Meints, K. (1999). Prototypes and the acquisition of the English passive. In B. Kokinov (Ed.), Perspectives on Cognitive science, Vol. 4, pp.67-77. Sofia: NBU Press.

Messenger, K., Branigan, H. P., \& McLean, J. F. (2011a). Evidence for (shared) abstract structure underlying children's short and full passives. Cognition, 121(2), 268-274.

Messenger, K., Branigan, H. P., \& McLean, J. F. (2011b). Is children's acquisition of the passive a staged process? Evidence from six- and nine-year-olds' production of passives. Journal of Child Language, 39(5), 991-1016.

Messenger, K., Branigan, H. P., McLean, J. F., \& Sorace, A. (2012). Is young children's passive syntax semantically constrained? Evidence from syntactic priming. Journal of Memory and Language, 66(4), 568-587.

Messenger, K., \& Fisher, C. (2018). Mistakes weren't made: Three-year-olds' comprehension of novel-verb passives provides evidence for early abstract syntax. Cognition, 178, 118 132.

Newmeyer, F. J. (2003). Grammar is grammar and usage is usage. Language, 79(4), 682-707.

Peter, M., Chang, F., Pine, J.M., Blything, R., Rowland, C.F. (2015). When and how do children develop knowledge of verb argument structure? Evidence from verb bias effects in a structural priming task. Journal of Memory and Language, 81, 1-15.

Pickering, M. J., \& Ferreira, V.S. (2008). Structural priming: A critical review. Psychological Bulletin, 134(3), 427-459.

Pinker, S. (1989). Learnability and cognition: The acquisition of argument structure. Cambridge, MA: MIT Press.

Pinker, S., Lebeaux, D. S., \& Frost, L. A. (1987). Productivity and constraints in the acquisition of the passive. Cognition, 26(3), 195-267.

R Core Team (2018). R: A language and environment for statistical computing. R Foundation for Statistical Computing, Vienna, Austria. http://www.R-project.org.

Ratcliff, R. (1993). Methods for dealing with reaction time outliers. Psychological Bulletin, $114(3), 510-532$. 
Rowland, C. F., Chang, F., Ambridge, B., Pine, J. M., \& Lieven, E. V. M. (2012). The development of abstract syntax: Evidence from structural priming and the lexical boost. Cognition, 125(1), 49-63.

Savage, C., Lieven, E. V. M., Theakston, A., and Tomasello, M. (2003). Testing the abstractness of children's linguistic representations: Lexical and structural priming of syntactic constructions in young children. Developmental Science, 6(5), 557-567.

Savage, C., Lieven, E. V. M., Theakston, A., and Tomasello, M. (2006). Structural priming as implicit learning in language acquisition: The persistence of lexical and structural priming in 4-year-olds. Language Learning and Development, 2(1), 27-149.

Schlesinger, I. M. (1981). Semantic assimilation in the development of relational categories. In W. Deutsch (Ed.). The child's construction of language, pp. 223-243. London: Academic Press.

Singmann, H., \& Kellen, D. (in press). An Introduction to Mixed Models for Experimental Psychology. In D. H. Spieler \& E. Schumacher (Eds.), New Methods in Neuroscience and Cognitive Psychology. Psychology Press

Standing, L. (1973). Learning 10000 pictures. The Quarterly journal of experimental psychology, 25(2), 207-222.

Sudhalter, V. \& Braine, M. D. S. (1985). How does comprehension of passives develop? A comparison of actional and experiential verbs. Journal of Child Language, 12(2), 455470.

Tomasello, M. (2003). Constructing a language: A usage-based theory of language acquisition. Cambridge, MA: Harvard University Press.

Valian, V., Solt, S., \& Stewart, J. (2009). Abstract categories or limited-scope formulae? The case of children's determiners. Journal of Child Language, 36(4), 743-778.

Yang, C. (2013). Who's afraid of George Kingsley Zipf? Or: Do children and chimps have language? Significance, 10(6), 29-34.

Zaki, S. R., Nosofsky, R. M., Stanton, R. D., \& Cohen, A. L. (2003). Prototype and exemplar accounts of category learning and attentional allocation: a reassessment. Journal of Experimental Psychology: Learning, Memory, and Cognition, 29, 6: 1160-1173.

Ziegler, J., Goldberg, A.E., \& Snedeker, J. (2018) Locative priming of passives is due to shared BY”. Poster presented at the 31st Annual CUNY Sentence Processing Conference, March, 2018.

Ziegler, J., Snedeker, J., \& Wittenberg, E. (2017). Priming is swell, but it's far from simple. Behavioral and Brain Sciences, 40. 


\section{Appendix A}

Verbs used in Experiment $1 . \mathrm{AP}=$ agent-patient verb, $\mathrm{ET}=$ experiencer theme verb, $\mathrm{TE}=$ theme-experiencer verb. ${ }^{*}$ denotes verbs also used in Messenger et al. (2012).

\begin{tabular}{|l|l|}
\hline \multicolumn{2}{|c|}{ List A } \\
\hline bite* $^{*}$ AP \\
\hline chase & AP \\
\hline hit* & AP \\
\hline kick & AP \\
\hline push & AP \\
\hline squash* & AP \\
\hline forget & ET \\
\hline hear* & ET \\
\hline know & ET \\
\hline love* & ET \\
\hline see* & ET \\
\hline understand & ET \\
\hline amaze & TE \\
\hline bother & TE \\
\hline impress & TE \\
\hline scare* & TE \\
\hline surprise* & TE \\
\hline upset* & TE \\
\hline
\end{tabular}

\begin{tabular}{|l|l|}
\hline \multicolumn{2}{|c|}{ List B } \\
\hline carry* & AP \\
\hline dress & AP \\
\hline hug & AP \\
\hline pat* & AP \\
\hline pull* & AP \\
\hline wash & AP \\
\hline hate & ET \\
\hline ignore* & ET \\
\hline like* & ET \\
\hline remember* & ET \\
\hline smell & ET \\
\hline watch & ET \\
\hline annoy* & TE \\
\hline frighten* & TE \\
\hline please & TE \\
\hline shock* & TE \\
\hline tease & TE \\
\hline worry & TE \\
\hline
\end{tabular}

\section{Appendix B}

Verbs used as primes and targets in Experiment 2. AP = agent-patient verb, ET = experiencer theme verb, TE $=$ theme-experiencer verb. ${ }^{*}$ denotes verbs also used in Messenger et al. (2012).

\section{Prime verbs}

Target verbs 


\begin{tabular}{|l|l|l|l|l|}
\hline \multicolumn{2}{|c|}{ all AP } & \multicolumn{1}{c|}{ AP } & \multicolumn{1}{c|}{ ET } & \multicolumn{1}{c|}{ TE } \\
\hline avoid & hold & bite* & forget & amaze \\
\hline bite* & hug & carry* & hate & annoy* \\
\hline call & kick & chase & hear* & bother \\
\hline carry* & kiss & dress & ignore* & frighten* \\
\hline chase & lead & hit* & know & impress \\
\hline cut & pat* & hug & like* & please \\
\hline dress & pull* & kick & love* & scare* \\
\hline drop & push & pat* & remember* & shock* \\
\hline eat & shake & pull* & see* & surprise* \\
\hline follow & squash* & push & smell & tease \\
\hline help & teach & squash* & understand & upset* \\
\hline hit* & wash & wash & watch & worry \\
\hline
\end{tabular}

